Discussion Paper No. 852

\title{
OPTIMAL DEPRECIATION SCHEDULES FOR REGULATED UTILITIES
}

\author{
by \\ William P. Rogerson \\ Department of Economics \\ Northwestern University \\ Evanston, IL 60201
}

September 1989

\footnotetext{
I would like to thank Ron Braeutigam, Kathleen Hagerty, Jay Hillman, John Panzar and Rob Porter for extremely helpful discussions. This work was supported by the Lynde and Harry Bradley Foundation and NSF Grant SES-8906751.
} 


\section{Introduction}

Production and distribution of electricity requires investment in long lived specialized facilities capital. The bulk of electricity in the United States is supplied by investor owned utilities. In this case the utility will initially purchase the facilities capital. It will then be allowed to recover its investment cost through the prices it charges consumers. The method for doing this is as follows. A depreciation schedule for the facilities capital is constructed. Then in any given year the firm is allowed to earn revenues in excess of operating costs by an amount equal to that year's depreciation charge plus a fair rate of return on the remaining book value. This sequence of annual payments is called the amortization schedule.

Economists have long recognized the fact that the goal of fairly reimbursing the firm for its asset purchases can be accomplished using any depreciation schedule so long as a fair rate of return is paid on the remaining book value. 1 This raises the question of what depreciation schedule should be chosen. Existing work on this subject suggests two conflicting answers depending on the problem one desires to solve. ${ }^{2}$ In order to optimally smooth consumer expenditures a relatively constant amortization schedule is desirable. However in order to prevent the hold-up problem from arising a relatively accelerated amortization schedule is desirable.

The major goal of this paper is to show that it is possible to design a regulatory institution which

(i) simultaneously smoothes consumer expenditures and accelerates payments to the firm, thereby solving both problems.

(ii) maintains the feature of the current system that no general tax revenues are used to fund the utility. 



\section{(ii) maintains whatever incentives for cost minimization which exist under the current system.}

In addition to this major result a number of other results are derived. First in order to prove (iii), a model of regulatory lag which explicitly models the amortization schedule for finite lived assets is constructed. As a byproduct of the analysis it is shown that the amortization schedule chosen affects the incentives provided by regulatory lag. In particular, the constant amortization schedule generates optimal incentives. Second, a related model is used to investigate the incentive properties of franchise auction schemes where assets are transferred at book value. Once again the amortization schedule used to calculate book value affects the incentive properties of the franchise auction scheme and the constant amortization schedule is shown to generate optimal incentives.

This paper is organized as follows. Section 2 gives a verbal description of existing theories, the proposed solution, and the major results. Sections 3 and 4 develop analytic models to prove the results which cannot be demonstrated verbally. Section 3 considers the incentive effects of regulatory lag. Section 4 considers franchise auctions. Finally Section 5 explains how the proposed system might cope with two special problems, construction work in progress and inflation.

\section{The Proposed System}

\section{A. Existing Theories}

The existing economics literature can be interpreted as suggesting two different theories of how to calculate an optimal depreciation schedule. Each theory focuses on solving a different problem. 
The first theory relies on the fact that current regulatory practice is to raise each year's revenue requirement for the utility from that year's prices. ${ }^{3}$ That is, revenues in year $t$ for the utility must be raised from consumer expenditures in year $t$. Therefore a variant of Ramsey pricing can be applied where electricity each year is viewed as a separate good. The optimal prices across time can be solved for given the constraint that the firm break even. These in turn determine the depreciation schedule.

In general one would expect it to be optimal for the path of prices to be relatively constant over time. This in turn implies that the amortization schedule should be relatively constant. In particular depreciation methods which result in very high prices initially and declining prices over time would not be optimal. Utility economists refer to such a price pattern as inducing "rate shock."

The second theory relies on ideas developed by williamson [1975, 1983, 1985] and Klein, Crawford, and Alchian [1978]. They argue that once any seller has invested in an asset with specific value to only one buyer, that the optimal myopic course of action for the buyer is to offer to pay for only the incremental (avoidable) costs of production. Faced with such a prospect the seller may choose to simply not invest or at least under-invest. This has been called the hold-up problem. In the context of public utility regulation, these theories highlight the problem that it is very difficult for society to credibly promise to give a firm a fair rate of return on its investments in specific assets for long periods into the future. Various doctrines which can be interpreted as requiring society to pay a fair rate of return on at least prudent investments provide some commitment ability. However the inherent lack of any objective measure of "fair rate of return" or "prudency" in 
reality creates substantial discretion for society to renege on its promises. Recently Gilbert [1982] and Gilbert and Newberry [1988] have built formal models applying the holdup concept to public utility regulation.

As the probability of being held-up increases, a utility will require a higher promised rate of return to compensate for this risk. If sufficiently high rates cannot be promised, or if the probability of being held-up approaches one, utilities will generally be unwilling to invest at all. In such a situation utilities will invest only the minimal possible amount, resulting in increased probabilities of shortages and a non-optimal capitalfuel ratio in their installed capacity.

The solution to this latter problem points in the direction of using accelerated depreciation. Presumably a commission's promises become less binding over time as members change, new governments are elected, and economic circumstances change. Thus a promise to pay a fair rate of return over 3 or 4 years is probably much more credible than one to pay a fair rate of return over 30 years. Of course the perfect solution is to choose an instantaneous depreciation schedule - - to reimburse the utility instantaneously for its capital expenditures.

Depreciation methods used in practice such as straight line depreciation are somewhat accelerated relative to a constant amortization schedule.

However substantial amortization payments continue through the life of the asset. Thus current methods are probably more oriented towards solving the problem of optimal smoothing of consumer expenditures than of preventing the hold-up problem. There is some evidence that the current system does suffer from the hold-up problem. For example many economists feel that the inflationary environment of the $1970^{\prime}$ s triggered a hold-up episode we may 
still be suffering from. ${ }^{4}$ Consumer (and therefore political) resistance to rising electricity prices forced regulatory commissions to reduce the rate of return earned by utilities below their cost of capital. Utilities responded by not installing capacity to the extent possible and installing gas turbines and other high fuel consumption generators instead of (arguably) more efficient capital intensive plants.

\section{B. The Proposed Systen}

To summarize the above discussion, current theory suggests that a radically different depreciation schedule would be optimal depending upon whether one wanted to smooth consumer expenditures or reduce the hold-up problem. The current system uses depreciation schedules which substantially solve the former problem but only at the cost of not dealing adequately with the latter problem.

The obvious solution to this dilemma would be to choose two different depreciation schedules, one determining consumer expenditures and the other determining the firm's revenues. Such a scheme would violate the rule that the utility's revenues in period $t$ equal the consumers' expenditures in period $t$. However this rule is not an end in and of itself. Rather it is simply a device to guarantee that general tax revenues do not intermingle with utility revenues. ${ }^{5}$ The major point of this paper is that one can keep utility revenues and general tax revenues totally separate without imposing this year-by-year equivalence. This in turn permits the design of regulatory institutions which simultaneously smooth prices for consumers and instantaneously depreciate capital for the firm. 
Specifically, the suggestion of this paper is that a government backed bond-issuing authority be established to operate in conjunction with the regulatory commission and public utility. At the instant an expenditure for an asset was entered into the rate base by the commission the expenditure would be instantaneously depreciated. The bond-issuing authority would raise sufficient funds to provide this reimbursement to the firm. Then the utility would be responsible each year for paying the bond-issuing authority sufficient funds to cover that year's amortization payments for the bonds. The utility's revenue requirement would be calculated to include the cost of these payments to the bond-issuing authority. The amortization schedule for the bonds would be chosen to generate the optimal pattern of prices for consumers over time. In particular it would probably be relatively constant (i.e., the holders of the bonds would receive a constant payment per period over a period equal to the estimated life of the asset). Note that the bondissuing authority breaks exactly even ex post in every state of the world. Thus no intermingling of utility revenues with general tax revenues is required.

An important function served by the utility's investment in sunk assets under the current system is that it forces the utility to absorb negative profits in years when the operation of incentive schemes such as regulatory 1 ag or prudency reviews causes these to occur. This is an important function and some device for accomplishing it must be created under the proposed system. Therefore the utility would be asked to post a "performance bond" which would be kept in an interest bearing account. If it gave up the franchise voluntarily or involuntarily it would forfeit the bond. 
In order to not create a new hold-up problem equal in magnitude to the existing one, the posted bond must be considerably smaller than the net book value of the firm's assets which is the size of the implicit bond currently posted. Therefore the desirability of the proposed system really hinges on whether one believes that the current size of the bond implicitly posted by utilities is too large - - i.e. - - if the costs created by exacerbating the hold-up problem outweigh the benefits created by having incentive schemes be able to impose much larger losses on the utility. This paper does not attempt to assess the answer to this question. Rather its goal is to show that an institutional device exists for accomplishing the following results.

(i) having the firm post a smaller bond

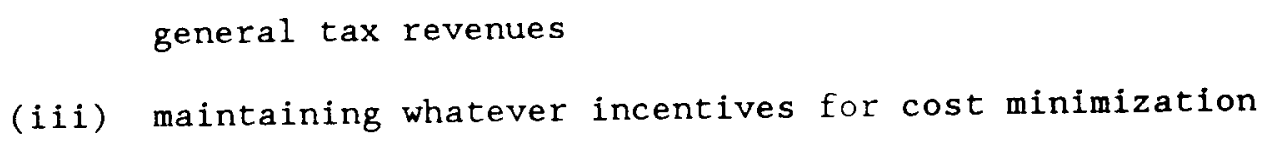
that exist under the current system, subject to the proviso that penalties larger than the bond cannot be imposed.

The fact that (i) and (ii) are true has been explained above. In order to address (iii) it will be useful to first address the issue of asset ownership under the proposed scheme. It would be possible to structure the scheme so that either party was the legal owner of the assets. These two variants will be called the utility ownership proposal (UOP) and the government ownership proposal (GOP). Under the utility ownership proposal the bond-issuing authority would legally lend the utility funds to purchase the asset. The utility's payments to the bond-issuing authority would be loan payments. The bond posted by the utility would be posted with the bondissuing authority as partial collateral for the loans. The bond would be 
forfeited and the bond-issuing authority would repossess all the assets if the utility ceased making payments. Under the UOP the legal relationship between the commission and the utility could continue much as under the current system. Under the GOP the government would legally purchase the assets and the utility's payments would be viewed as rental payments. The bond would be posted with the utility commission. The utility would promise to continue renting the assets over the long run and would forfeit its bond if it ceased to do so. Under the GOP the relationship between the commission and utility would change fundamentally from one governed by the current set of somewhat nebulous legal precedents to one governed by an explicit management contract between the commission and the utility. This is because many of the legal doctrines governing the current relationship presuppose that the utility owns the assets. Thus they would no longer apply and would have to be replaced by an explicit contract governing such factors as how the gain or loss from asset dispositions would be shared.

\section{Properties of the Proposed Systen}

The question of incentives under the proposed system can now be addressed. There are basically two types of incentives operating on utilities to encourage them to be efficient. The first is regulatory lag. This essentially allows the utility to keep any cost-savings it generates for a period of time before rates are adjusted downward. The second type of incentive will be called commission reviews. The commission performs reviews of all utility expenditures and can disallow any expenditures which it feels were wasteful or not prudent. Furthermore it can force the utility to absorb at least some losses associated with early retirement of assets which are no 
longer useful, even if the cause of obsolescence was totally unforeseeable and the utility cannot be accused of lack of prudency.

It will be shown in Section 3 that both the GOP and UOP continue to provide the same incentives due to regulatory lag as exist under the current system. ${ }^{6}$ This is not immediately obvious and requires analytic proof. In order to do this a model which explicitly considers finite lived assets and the amortization schedule used to finance the asset is constructed. Under the proposed system the amortization schedule determines both the payments of the utility to the bond-issuing authority and the allowed revenue requirement of the utility. It is shown that for a given amortization schedule and given length of regulatory lag that the utility will choose the same inputs under the GOP, the UOP and the current system. A second result of independent interest is also proven. The choice of amortization schedule affects the incentive properties of regulatory lag. In particular the utility will choose a capital labor ratio equal to (less than, greater than) the first-best ratio if the amortization schedule is equal to (accelerated relative to, decelerated relative to) the constant amortization schedule. This result has not been previously shown in the regulatory lag literature to the best of my knowledge. This is because the existing literature does not explicitly model the amortization schedule. ${ }^{7}$ Thus an independent reason in addition to smoothing consumer expenditures exists for choosing a constant amortization schedule under the proposed scheme and the current scheme.

The question of whether the proposed system maintains the incentives the current system provides through regulatory review will now be considered. The GOP should continue to provide exactly the same incentives since the current legal framework determining the commission's rights and 
responsibilities can continue to be applied. ${ }^{8}$ This is because the utility is still the owner of the assets. The situation under the UOP is more complicated. Since government now is the legal owner of the assets the existing legal framework will not apply and an explicit contractual relationship will take its place. If totally complete contracts governing absolutely all aspects of the parties' behavior could be costlessly drafted and perfectly enforced, the question of legal ownership would be irrelevant. One could simply draft a contract which assigned rights and responsibilities in exactly the same fashion as results from the current system. However, in practice it is unlikely that exactly the same ill-defined and nebulous rights and responsibilities as exist under the current system could be reproduced by an explicit contract.

Therefore in order to reproduce exactly the same incentives as exist under the current system the UOP should be selected. However the GOP might provide an opportunity to improve incentives by replacing the current set of nebulous and ill-defined review rights by more explicit well-chosen procedures. This subject will not be further explored in this paper.

A final issue investigated by this paper is the feasibility of franchise auctions. Demsetz [1968] suggested that cost-based regulation could be replaced by periodic auctions where potential franchise holders would "bid" a description of their proposed rates and service characteristics. Since Demsetz, many authors have pointed out that a number of serious problems stand in the way of implementing such a system. ${ }^{9}$ Chief among these problems is the existence of specific assets. When an investor-owned utility purchases specific assets for generating and distributing electricity in an area of 
service, some method for transferring these assets must be arranged in the event that a new firm wins the auction.

The issue raised in the context of this paper is that the proposed system appears to provide a method for finessing the specific asset problem. Under the GOP government owns the assets. Thus it could hold periodic auctions subject to the proviso that the winner would assume the responsibility for rental payments. Even under the UOP one could accomplish essentially the same function by legally requiring the current franchise-holder to give his assets to a new incumbent, in return for the incumbent assuming the obligation to make payments to the bond-issuing authority.

The major point made by this paper regarding franchise auctions is that an essentially equivalent arrangement could be created under the current system as we11, by requiring the existing franchise holder to sell its assets to a new incumbent at their book value. Thus the superficial appearance that government ownership of capital under the proposed system makes running an auction easier is incorrect. Under the proposed system government would still calculate amortization schedules for capital assets to determine payment levels from the utility to the bond-issuing authority. Under the current system equivalent incentives can be created if government is willing to perform the same amortization calculations in order to determine book values.

This has two implications. First, on a negative note, there is no advantage created by switching to the proposed system in order to facilitate the implementation of the franchise auctions. Second, on a more positive note, the analysis raises the question of whether franchise auctions under the proposed system, or modified franchise auctions where book value calculations 
are performed under the current system, would be a workable scheme. If so, specific assets are not a problem for implementing franchise auctions.

The claim that franchise auctions provide the same incentives for cost minimization under the GOP, UOP and current systems requires analytic proof. This is provided in Section 4. A model which explicitly considers finite lived assets and their amortization schedules is considered. Under the proposed system, the amortization schedule determines the payments made by the current franchise holder to the bond-issuing authority. Under the current system, the amortization schedule determines the book value of the assets which is the transfer price when the franchise changes hands. It is shown that, for any given amortization schedule, the utility will choose the same inputs under the GOP, the UOP, and the current system. A number of other results of independent interest are also shown. First, the amortization schedule used affects the nature of incentives provided by franchise auctions. In particular, the utility will choose a capital labor ratio which is equal to (less than, greater than) the first best ratio if the amortization schedule is equal to (accelerated relative to, decelerated relative to) the constant amortization schedule. Second, the comparative performance of regulatory lag and franchise auctions can be assessed. In many cases they provide equivalent incentives for cost minimization. However, franchise auctions create superior incentives when cost-reducing innovations cannot be transferred to new incumbents. Of course the other advantage of franchise auctions is that all rents accrue to consumers. Under regulatory lag rents accrue to the firm during the periods of lag. 


\section{Regulatory Lag}

\section{A. Introduction}

The major purpose of this section is to show that the current and

proposed systems create the same incentives for cost-minimization due to regulatory lag. Part B discusses amortization schedules. Part C describes the basic model of regulatory lag in which the firm makes a capital labor input mix decision. Parts $D$ and $E$ analyze this basic model. Part F considers an alternate version of the model where the firm can engage in unobservable effort in order to lower production cost.

\section{B. Anortization Schedules}

It will be useful to introduce some notation and a few simple facts regarding amortization schedules. An $(n, R)$ amortization schedule will be defined to be an $n$-tuple of real numbers $\left(a_{1}, \ldots, a_{n}\right)$ such that a loan of $k$ dollars in period 0 would be fully paid back given the interest rate $R$ by payments of $a_{i} k$ in period $i$ for $i=1, \ldots, n$. Formally this is defined as follows .

\section{Definition}

An $(n, R)$ amortization schedule is a vector of real numbers $a=\left(a_{1}, \ldots, a_{n}\right)$ satisfying

$$
\sum_{i=1}^{n} \frac{a_{i}}{(1+R)^{i}}=1
$$


Any amortization schedule can be viewed as being created through a system of paying an annual charge equal to depreciation plus interest on the remaining value (or book value) of the loan. This can be formally defined as follows.

\section{Definition}

Let $a=\left(a_{1}, \ldots, a_{n}\right)$ be an $(n, R)$ amortization schedule. Then the ordered tuples $d=\left(d_{1}, \ldots, d_{n}\right)$ and $b=\left(b_{0}, b_{1}, \ldots, b_{n}\right)$ are, respectively, the depreciation schedule given a and the book value schedule given a if they satisfy the following:

(3.2) $\quad b_{0}=1$

(3.3) $\quad d_{t}=a_{t}-R b_{t-1}$

(3.4) $\quad b_{t}=b_{t-1}-d_{t}$

Then $d_{t} k$ is interpreted as the depreciation during period $t$ and $b_{t} k$ is interpreted as the book value of the loan at the end of period $t$.

Reorganizing (3.3) yields

$$
a_{t} K=d_{t} K+R b_{t-1} K
$$

Therefore the period $t$ payment equals period $t$ depreciation plus interest on the end of period $t-1$ book value of the loan. 
It is also straightforward to show that (3.1) implies that

(3.6) $\sum_{i=1}^{n} d_{i}=1$.

Conversely, if one chooses any depreciation schedule $\left(d_{1}, \ldots, d_{n}\right)$ such that (3.6) holds and then uses (3.2) - (3.4) to define an amortization schedule, then (3.1) holds. Therefore, the amortization schedule exactly pays back the loan including interest if and only if the associated depreciation schedule fully depreciates the asset.

Two particular amortization schedules will be of particular interest so they will be defined now.

\section{Definition:}

The constant amortization schedule has $a_{t}$ constant for every $t$. This constant value is given by

$$
a_{t}=\frac{R}{\phi(n)}
$$

where

$$
\phi(n)=1-\frac{1}{(1+R)^{n}}
$$




\section{Definition:}

The straight line amortization schedule has a constant depreciation charge per period equal to $1 / \mathrm{n}$.

Finally it will be useful to define a notion of speed of amortization. For any $(n, R)$ amortization schedule, $a$, let $a^{t}$ denote the present value of payments through period $t$.

$$
a^{t}=\sum_{i=1}^{t} \frac{a_{i}}{(1+R)^{i}}
$$

Then one amortization schedule will be said to be accelerated relative to another if the present value of payments is higher for every $t$.

\section{Definition:}

Let $a$ and $\hat{a}$ be two $(n, R)$ amortization schedules. Then a is accelerated relative to $\hat{a}$ (or equivalently $\hat{a}$ is decelerated relative to a) if

$$
\text { (3.10) } \quad a^{t} \geq \hat{a}^{t}
$$

for every $t=1, \ldots, n$.

Not surprisingly, the speed at which depreciation accumulates is an equivalent measure. For a depreciation schedule d define $d^{t}$ to be accumulated depreciation up to period $t$.

$$
d^{t}=\sum_{i=1}^{t} d_{i}
$$


Proposition 1 now states this result. Since the proof is straightforward it is omitted.

\section{Proposition 1:}

Let $\mathrm{d}$ and $\hat{\mathrm{d}}$ be the depreciation schedules for, respectively a and $\hat{\mathrm{a}}$. Then $a$ is accelerated relative to $\hat{a}$ if and only if

(3.12) $\quad d^{t} \geq \hat{d}$

for every $t=1, \ldots, n$.

This implies the following simple Corollary which will also be stated without proof.

\section{Corollary 1:}

Let $\mathrm{d}$ and $\hat{\mathrm{d}}$ be the depreciation schedules for a and $\hat{a}$. Suppose that $\mathrm{d}$ increases over time and $\hat{d}$ decreases over time -- i.e. - -

(3.13)

$$
d_{t} \leq d_{t+1}
$$

$$
\hat{\mathrm{d}}_{t} \geq \hat{\mathrm{d}}_{t+1}
$$

for every $t=1, \ldots, n-1$. Then 
(i) $\hat{a}$ is accelerated relative to a.

(ii) $\hat{a}$ is accelerated relative to the straight line amortization schedule

(iii) a is decelerated relative to the straight line amortization schedule.

Note in particular that the constant amortization schedule implies increasing depreciation payments. Most depreciation methods used in practice other than straight 1 ine involve decreasing depreciation payments. Therefore by Corollary 1 , constant amortization is decelerated relative to all methods normally used in practice, including straight line. Straight line amortization is decelerated relative to all other methods normally used.

\section{Case \#1 (Input Substitution): Description}

In order to focus on the incentives provided by regulatory lag it will be assumed that no prudency reviews or "used and useful" reviews occur. Furthermore no assets are ever sold before the end of their lifetime. Therefore GOP and UOP are identical and will simply be referred to as the proposed system.

The firm is currently in period 0. It must produce $x$ units of output per year in periods 1 through $\infty$. Output is produced according to the production function

$$
\mathrm{x}=\mathrm{F}(\mathrm{K}, \mathrm{L})
$$


where $\mathrm{K}$ denotes the dollar value of capital and $\mathrm{L}$ denotes the dollar value of labor. It will be assumed that the isoquant defined by (3.15) is strictly decreasing and strictly convex.

The firm initially chooses a level of capital in period 0 which lasts $n$ periods. Therefore it will purchase a new asset in period $n$ to produce in periods $n+1$ through $2 n$, a new asset in period $2 n$ to produce in periods $2 n+1$ through $3 n$, etc. The firm chooses a level of labor usage in each period to satisfy (3.15) given its capital stock.

It will be assumed that there is a single cost of capital, denoted by $R$, at which both the firm and bond-issuing authority can borrow money. The reason for this assumption can be explained as follows. Under either system the utility is delegated the responsibility for choosing a capital labor ratio given the input costs. There are two effects on this choice when one switches from the current system to the proposed system. First the incentives facing the firm may change. Second, the cost of capital will change if the firm's cost of borrowing is different from that of the bond-issuing authority. This is because capital to construct facilities is borrowed at the firm's cost of capital under the current system and the bond-issuing authority's cost of capital under the proposed system. In order to eliminate this second effect it is assumed that both costs of capital are the same. Thus any change in the firm's capital labor choice when we move from one system to another can be solely ascribed to the changed incentives. Conversely, if the capital labor choice does not change between systems, one can conclude that both systems provide the same incentives. 10

It will be assumed that the same $(n, R)$ amortization schedule is used under both systems. That is, the amortization schedule used under the current 
system to determine revenue requirements is the same as that used under the proposed system to determine payments from the utility to the bond-issuing authority. Let $a=\left(a_{1}, \ldots, a_{n}\right)$ denote the $(n, R)$ amortization schedule. It will turn out that the amortization schedule used affects the firm's incentives. However, the two systems will still be shown to produce equivalent incentives in the sense that the firm will choose the same inputs under either system for a given amortization schedule.

In order to describe the nature of regulatory lag in this model it will be useful to first explain how the model would work with no regulatory lag. In the absence of regulatory $1 \mathrm{gg}$ the systems would work as follows. Suppose the firm purchases an asset in period ni where $i \in\{0,1,2, \ldots\}$ for $K$ dollars and then uses $L$ dollars of labor in periods $n i+t$ for $t \in\{1, \ldots, n\}$. Then under both systems the firm's revenue requirement would be

$$
a_{t} K+L
$$

in period $n i+t$ for $t \in\{1, \ldots, n\}$.

The manner in which regulatory lag alters this behavior will now be described. It will be assumed that the commission holds a rate hearing every $\mathrm{m}$ years and that $\mathrm{m}$ divides evenly into $\mathrm{n}-\mathrm{i}$.e. -
(3.17)

$$
\mathrm{n}=\mathrm{i}^{\star} \mathrm{m}
$$

for some integer $i^{*}$. This means that the commission meets $i^{*}$ times during the lifetime of any asset. During each rate hearing the commission observes the current amount of capital being used for production and its age. It sets 
revenue requirements for the next m periods according to (3.16) assuming that the same asset will continue to be used. If the current asset will wear out during the next m periods the commissions sets revenue requirements under the assumption that a new asset will be purchased which is identical to the old asset.

The commission's first hearing is in period 0 . Then it meets in periods $m, 2 m, 3 m$, etc. It will be assumed that the utility chose levels of capital and labor equal to $\mathrm{K}^{\star}$ and $\mathrm{L}^{\star}$ in previous periods and that the current capital will wear out at the end of period 0 . When the commission meets in period 0 it assumes the replacement asset will be identical to the current asset and it therefore sets revenues for periods 1 through $m$ according to

$$
p_{t}^{*}=a_{t} K^{*}+L^{*}
$$

In period $m$ it meets again. This time it will observe the level of capital usage and labor usage which the firm actually chose in period 0 . Suppose these are $K$ and $L$. Then revenues in period $t$ for $t \in\{m+1, \ldots, 2 n\}$ will be set according to (3.16). This process will continue until period $n$. When the commission meets in period $n$ it will set revenue requirements for periods $n+$ 1 through $\mathrm{n}+\mathrm{m}$ under the assumption that a new asset of value $K$ will be purchased. The process then continues in the same fashion.

Three remarks should be noted about this process. First, in order for regulatory $\operatorname{lag}$ to exist it is assumed that the commission cannot observe the firm's next choice of capital when it meets during periods $0, n, 2 n$, etc.

Second, for simplicity it is assumed that the commission actually sets revenue requirements which vary over time. For example, if a declining 
amortization schedule is used, then the revenue requirement schedule set at a hearing will decline over the next m years. In reality a commission would probably be more likely to set a constant revenue requirement whose net present value equals the net present value of the declining requirement schedule. It is clear this would not change any of this paper's results. Therefore in order to simplify the exposition, the notationally simpler assumption that the commission sets time-varying revenue requirements has been made.

Third it is clear that the firm will make the same capital decision at every time since the decision problem is the same. In particular this means that one can analyze the firm's problem by assuming that it chooses a single value for the capital stock and that it always buys a machine of this value. Therefore the firm earns zero economic profit beginning with its second asset purchase. This means that the firm's maximization problem can be solved by only considering revenues and costs from periods 1 through $n$. This will be done in the following analysis.

Fourth, one can interpret this model as capturing a situation where some aspect of technology or demand suddenly changes in period 0 . However the new technology and demand conditions will stay constant at their new values forever. The firm makes an adjustment to the new conditions and earns potentially positive or negative economic profit during the ensuing meriods of regulatory lag. Because technology and demand stay constant the firm continues to choose the same input values in all future periods and thus revenue requirements set by the commission do not lag behind the firm's decision after period $m$. Thus this is a "one-shot" model of regulatory lag. A more complex and realistic model would allow demand and/or technology to 
constantly change in an unpredictable fashion. In such a model the firm would be continually changing its input mix and the regulator's decisions would be continually lagging behind.

To finish a description of the model the first best capital labor choice will be defined. It will be assumed that a unique first best outcome exists.

\section{Definition:}

The first best capital labor choices are the solution to the following program.

$$
\underset{K, L}{\operatorname{Minimize}} \quad K+\frac{\phi(n)}{R} L
$$

$$
\text { subject to } x=F(K, L)
$$

The second term of (3.19) is the discounted present value of spending $L$ dollars per year in periods 1 through $n$. Recall that $\phi(n)$ is defined by (3.8)

\section{Case \#1: (Input Substitution): Analysis}

The cash flows experienced by the firm given it chooses capital $\mathrm{K}$ and labor $\mathrm{L}$ are as follows: 
Table 3.1

\section{Cash Flows for Case \#1}

\section{Period}

0

$t \in(1, \ldots, m)$

$t \in\{m+1, \ldots, n\}$
Current System

$-\mathrm{K}$

$p_{t}^{*}-L$

$a_{t}{ }^{K}$
Proposed Systen

0

$p_{t}^{*}-a_{t} K-L$

0

Under the current system the firm pays $\mathrm{K}$ dollars initially. During the periods of regulatory lag it receives $p_{t}^{*}$ each period and incurs $L$ dollars of labor cost. In subsequent periods the firm's revenue requirement equals (3.16). It incurs labor costs of $L$. Therefore its net cash flow is $a_{t} K$. Under the proposed system the firm incurs no costs in period 0 because the capital purchase is instantaneously depreciated. Then during each period of regulatory lag it pays the bond-issuing authority $a_{t} K$, incurs labor costs of $L$, and receives $p_{t}^{*}$. In subsequent periods the firm's revenue requirement and incurred costs both equal (3.16). Therefore its net cash flow is zero.

Proposition 2 now presents the net present value of the cash flows under each system and, in particular, shows that they are equal.

\section{Proposition 2:}

In Case \#1, the net present value of cash flows under both systems are equal and given by

$$
V(K, L, a)=\sum_{t=1}^{m} \frac{p_{t}^{*}}{(1+R)^{t}}-\frac{\phi(m)}{R} L-\left(\sum_{t=1}^{m} \frac{a_{t}}{(1+R)^{t}}\right) K .
$$


proof:

Substitute (3.1) and (3.8) into the NPV expressions.

QED .

An immediate Corollary of this is that the firm chooses the same values

of capital and labor under either system. This is because it maximizes (3.21)

subject to (3.20) under either system. This is stated as Corollary 2.

\section{Corollary 2:}

The firm makes the same capital labor choices under either system.

proof:

As above.

QED.

Corollary 3 new describes how the firm's input choices (under both systems) vary as the amortization schedule which is used varies.

\section{Corollary $3:$}

(i) The firm chooses the optimal capital labor ratio for every $\mathrm{m} \in(1, \ldots, \mathrm{n})$ if and only if $\mathrm{a}$ is the constant amortization schedule.

(ii) The firm chooses too low (high) a capital labor ratio for every $\mathbf{m} \in\{1, \ldots, \mathrm{n}\}$ if and only of $\mathrm{a}$ is accelerated (decelerated) relative to the constant amortization schedule. 
proof:

(i) A comparison of (3.19) and (3.21) shows that the firm's choice will be optimal for a given $m$ if and only if

$$
\sum_{t=1}^{m} \frac{a_{t}}{(1+R)^{t}}=\frac{\phi(m)}{\phi(n)} .
$$

Therefore an amortization schedule results in the optimal choice for every m if and only if (3.22) is true for every $m \in\{1, \ldots, n\}$. This produces $n$ linear equations in $n$ unknowns. Solving these equations shows ${ }_{t}$ is the same for every $t$ and given by (3.7).

(ii) The capital labor ratio chosen by the firm will be too high (too low) if the equal sign in (3.22) is replaced by $a \leq(\geq)$ sign. Let $a^{*}-\left(a_{1}^{*}, \ldots, a_{n}^{*}\right)$ denote the constant amortization schedule. By part (i) this satisfies (3.22) with equality. Therefore a given schedule will result in too high (too low) a capital labor ratio if

$$
\text { (3.23) } \quad a^{m} \geq(\leq) a^{\star m}
$$

where the superscript notation is defined by (3.10). In particular, then, by definition (3.11), a given schedule will result in too high (too low) a capital labor ratio for every $m$ if and only if it is decelerated (accelerated) relative to $a^{*}$.

QED.

Corollary 3 shows that an entirely separate reason exists for determining an optimal amortization schedule for a finite lived asset, independent of the consumer expenditure smoothing reason discussed in the literature. This 
reason applies to both the current system and the proposed system. Regulatory lag generates the first-best incentives if and only if the constant amortization schedule is chosen. A number of remarks should be noted about this result.

First, as described in Section B, all amortization schedules actually used in practice under the current system are accelerated relative to the constant amortization schedule. Therefore they should cause the utility to under-invest in capital in the absence of any other incentive effects.

Second there is perhaps one sense in which the efficiency result in part (i) of Corollary 3 is more "robust" for the proposed system than the current system. The efficiency result for the current system requires society to correctly estimate the firm's cost of capital. If society paid the firm more (less) than its true cost of capital it is straightforward to show that the firm will choose too high (low) a capital labor ratio. The same problem does not arise under the proposed system. The bond authority's cost of capital is objectively known and this is charged to the firm. Even if the firm has a different private discount rate this will not affect its incentives to choose the optimal capital labor ratio. This is because the firm experiences a cost of $\mathrm{aK}+\mathrm{L}$ every period during the regulatory lag (where a is the constant amortization rate). Since it does not have to compare different cash flows in different periods, its own discount rate is irrelevant when it optimizes profits. It simply minimizes aK $+\mathrm{L}$ subject to producing $x$. Therefore the proposed system will work well regardless of whether or not the commission knows or can estimate the firm's discount rate. However, the current system works best only if this discount rate can be estimated. Therefore, in this limited sense, the proposed scheme may provide superior incentives. 


\section{E, Case \#1 (Input Substitution): Analysis, Continued}

The conclusion of this section, that the proposed system preserves the incentives provided by regulatory lag, depends critically on a particular feature of the proposed system which might easily pass unnoticed if not specifically highlighted. Namely, when the utility purchases capital equipment, its rental payments to the bond-issuing authority are affected immediately. However the price it is allowed to charge consumers does not automatically change. Rather, the price remains constant until the next rate hearing. This section will conclude by showing that if capital costs were automatically passed through to affect prices immediately, then the utility would have an incentive to over-capitalize. This will clarify the reason why the proposed system preserves the incentives provided by regulatory lag.

Consider the following regulatory system, which will be called the modified proposed system. Under this system government instantaneously depreciates all facilities capital and finances this expenditure through a bond-issuing authority. Similarly, the bond-issuing authority recovers its amortization costs from the firm through annual payments. The difference is that under the modified proposed system the capital cost is automatically passed through to affect revenues. That is, as soon as the firm purchases capital its revenue requirement is adjusted to reflect its added costs. Similarly, if capital were sold the revenue requirement would be adjusted downward.

The cash flows for a firm choosing $K$ and $L$ are now as follows. 
Table 3.2

\section{Cash Flows Under The Modified Proposed Systen}

\section{Period}

0
$t \in\{1, \ldots, m\}$
$t \in(m+1, \ldots, \infty)$

\section{Cash Flow}

0

$L^{*}-L$

0

In period 0 the firm is immediately reimbursed for its capital expenditures so net cash flow is zero. In the periods of regulatory lag the revenue requirement is adjusted to reflect the changed capital stock. The revenue requirement in period $t$ is therefore

$$
a_{t} K+L^{*}
$$

where $K$ is the actual capital choice of the firm and $L^{*}$ is the historic labor choice. The firm pays ${ }_{t} \mathrm{~K}$ to the bond-issuing authority and $\mathrm{L}$ to labor. Therefore its net cash flow is

$$
L^{*}-L
$$

In periods after the regulatory $\mathrm{lag}$ is over the firm's revenue requirement equals its expenditures so net cash flow is zero.

From Table 3.2 it is clear that the firm maximizes its profits by maximizing capital usage and minimizing labor usage. The intuitive reason for this is clear. When capital costs are immediately passed through government is making the following offer to the firm. 


\begin{abstract}
"Buy a machine now. I'll pay for it immediately. If you save any labor costs you can keep the savings for m years."
\end{abstract}

Obviously the firm will find it advantageous to purchase as much capital as possible.

The reason for analyzing this example was to show that the intuition that "if government purchases capital, firms will buy too much" implicitly depends on the assumption that capital costs are passed through immediately. However there is no need to do this. Without this analysis, it might have been tempting to create a pass-through provision. After all, when a firm purchases capital, government has to adjust the amount the firm is responsible to pay the bond-issuing authority. Therefore it might seem "fair" to simultaneously adjust the revenue requirement. However, the above example shows that this should definitely not be done. The proposed system was purposed designed to not pass through capital costs automatically and this plays a key role in creating its desirable incentive properties.

\title{
F. Case \#2; Unobservable Effort
}

Thus far the existence of regulatory lag has been able to produce firstbest outcomes given that constant amortization schedules are used. This result does not accord well with many observers' impressions that utilities are far from perfectly efficient. In the real world the reason that regulatory lag cannot induce perfect efficiency is that reductions in cost often require the firm to take actions that reduce the firm's or its managers welfare without affecting accounting measures of cost. For example, if a 
utility operates in some unregulated markets, the cost of identifying opportunities for waste reduction may be having its managers spend less time on the commercial business, thereby reducing commercial profits. As another example, even if the firm is a single-product fully regulated utility, it may be that reducing waste requires extra managerial effort. In either case, the firm has to incur a private non-observable (to the regulator) cost to reduce waste.

This added note of realism will now be incorporated into the model. It will be shown that in this more realistic model costs are not reduced as much as would be first-best in either system. However the major point of this section still holds. The incentives for cost-reduction are the same under either system. Thus the conclusion that both the current and proposed system create the same incentives given regulatory lag is shown to hold in a more realistic mode1.

For simplicity the capital labor input substitution choice will be ignored. It will be assumed that in period 0 the firm makes two choices, $\mathbf{e}_{L}$ and $e_{K}$, where $e_{L}$ denotes a private unobservable expenditure which reduces labor expense in all subsequent periods and $e_{K}$ denotes a private unobservable expenditure which reduces capital expense in all subsequent periods. Let $L\left(e_{L}\right)$ and $K\left(e_{K}\right)$ denote the resulting amounts of labor and capital used. Assume that both functions are strictly positive, strictly decreasing, and strictly convex.

The first-best effort levels are defined as follows. It will be assumed that unique first-best effort levels exist. 


\section{Definition:}

The first-best effort levels solve the following program.

$$
\underset{e_{K} e_{L}^{M i n i m i z e}}{\operatorname{ma}} e_{K}+e_{L}+\Gamma\left\{K\left(e_{K}\right)+\frac{\phi(n)}{R} L\left(e_{L}\right)\right\}
$$

where

$$
\Gamma=\frac{(1+R)^{n}}{(1+R)^{n}-1}
$$

The expression in (3.26) is the discounted total production cost including effort. The constant $\Gamma$ reflects the fact that effort causes reductions in input cost for all periods in the future, and not just the first $n$ periods.

The equilibrium choices of the firm under both systems can now be investigated. As in the basic case the firm earns zero economic profit beginning with its second asset purchase in period $n$. Therefore only cash flows associated with the initial asset purchase need to be considered. These are as follows:

Table 3.3

\section{Cash Flows for Case \#2}

\section{Period}

0

$t \in(1, \ldots, m)$

$t \in\{m+1, \ldots, n\}$
Current Systen

$-K\left(e_{K}\right)-e_{K}-e_{L}$

$p_{t}^{*}-L\left(e_{L}\right)$

$a_{t} K\left(e_{K}\right)$
Proposed System

$$
\begin{aligned}
& -e_{K}-e_{L} \\
& p_{t}^{*}-a_{t} K\left(e_{K}\right)-L\left(e_{L}\right) \\
& 0
\end{aligned}
$$


The reasoning underlying the construction of Table 3.3 is essentially the same as for Table 3.1 so will not be repeated.

Proposition 3 now presents the net present value of the cash flows under each system and, in particular, shows that they are equal.

\section{Proposition 3:}

In Case \#2, the net present value of cash flows under both systems are equal and given by

$$
V\left(e_{K}, e_{L}, a\right)=-e_{K}-e_{L}+\sum_{t=1}^{m} \frac{p_{t}^{*}}{(1+R)^{t}}-\frac{\phi(m)}{R} L\left(e_{L}\right)-\left(\sum_{t=1}^{m} \frac{a_{t}}{(1+R)^{t}}\right) K\left(e_{K}\right) .
$$

proof:

The same as for Proposition 3.

QED .

An immediate corollary of this is that the firm chooses the same effort levels under either system. This is because it maximizes (3.28) under either system. This is stated as Corollary 4.

\section{Corollary 4:}

The firm makes the same effort level choices under either system.

\section{proof:}

As above. 
Corollary 4 makes the major point of this sub-section. Both systems create the same incentives. Corollary 5 will now complete the analysis by showing that the model of this section has the "realistic" feature that less than first-best effort levels are chosen.

\section{Corollary 5:}

The firm's effort levels are strictly less than the first-best.

proof:

Consider $e_{L}$. By (3.26) the optimal value of $e_{L}$ minimizes
(3.29)
$e_{L}+\frac{\Gamma \phi(n)}{R} L\left(e_{L}\right)$

By (3.28) the equilibrium level minimizes

$$
e_{L}+\frac{\phi(m)}{R} L\left(e_{L}\right)
$$

Since $m \leq n$, this implies that $\phi(m)$ is less than or equal to $\phi(n)$. By (3.27), $\Gamma$ is strictly greater than 1 . Therefore,

$$
\frac{\Gamma \phi(\mathrm{n})}{\mathrm{R}}>\frac{\phi(\mathrm{m})}{\mathrm{R}}
$$

Since $L$ is strictly decreasing and strictly convex this implies that the equilibrium choice of $e_{L}$ is strictly less than the optimal choice. The proof for $e_{K}$ is similar. 


\section{Auctions For Franchise Rights}

\section{A. Introduction}

This section formally models the incentive properties of franchise auction schemes under the current and proposed systems. Since the motivation for considering this topic was described in Section 2, it will not be repeated here. As in Section 3, the analysis will be carried out for two different models of input choice. Part B will consider the input selection model. Finally Part $\mathrm{C}$ will consider the unobservable effort model.

\section{B. Case \#1: Input Substitution}

Suppose the demand and production environment is as described for Case \#1 in Section 3. However, now interpret $m$ as the length of time a firm is allowed to hold the franchise until a new auction is held. Also assume that there are a potentially infinite number of identical firms which would be capable of operating the franchise.

The franchise operation will be run as follows under the current system. The government will announce an amortization schedule, $a=\left(a_{1}, \ldots, a_{n}\right)$ for capital which will determine the book value of assets at any time. Let $b=\left(b_{1}, \ldots, b_{n}\right)$ be the associated book value schedule. In period 0 firms will bid an annual revenue requirement. The low bidder wins the franchise at the price it bid. He then chooses a capital stock, $K$, in period 0 and pays for it. For each of the next m periods, the new franchise holder receives the revenue requirement he bid and pays for sufficient labor to produce $x$ units per period. Then, at the end of period $m$, a new auction is held. If a different firm wins, the new winner pays the previous incumbent $b_{m} k$ dollars for the assets. The new incumbent then produces $x$ units per year for $m$ years 
and receives the annual revenue requirement it bid. At the end of $m$ years another auction is held and the process continues indefinitely. Every $n$ years the winner of the auction must purchase a new asset.

Under the proposed system the government announces an amortization schedule, $a=\left(a_{1}, \ldots, a_{n}\right)$, which determines rental payments of the franchise holder. Firms also bid an annual revenue requirement in period 0 . The low bidder wins. The low bidder chooses a capital stock $\mathrm{K}$, in period 0 . However, the bond-issuing authority pays for it. Then in each period the firm receives the annual revenue requirement it bid, pays the bond-issuing authority $a_{t} k$ dollars and pays for sufficient labor to produce $x$ units. At the end of period $m$ a new auction is held. The low bidder receives the franchise. For each of the next m periods the new franchise-holder receives the revenue requirement it bid, pays the bond-issuing authority $a_{t} \mathrm{~K}$ dollars and pays for sufficient labor to produce $x$ units per period. After $m$ years a new auction is held and the process continues indefinitely. Every $n$ years the winner of the auction decides what type of new asset to purchase.

The outcome under each system will now be calculated. This will be done by working backwards. First the winning firm's capital labor choice will be calculated given it bid some annual revenue requirement $\mathrm{p}^{*}$. The capital labor choice will be seen to be independent of $\mathrm{p}^{\star}$. Therefore the equilibrium bid, $\mathrm{p}^{*}$, will simply be the value such that the winner earns zero economic profit given the predicted capital and labor choices. 11

It is clear that whether the firm is in period $0, n, 2 n$, etc. will not affect its capital labor choice. Without loss of generality assume that the firm has just won the auction in period 0 . The cash flows given it chooses $\mathrm{K}$ and $\mathrm{L}$ are as follows. 
Table 4.1

\section{Cash Flows for Case \#1}

\section{Period}

0

$t \in(1, \ldots, m-1)$

m

\section{Current System}

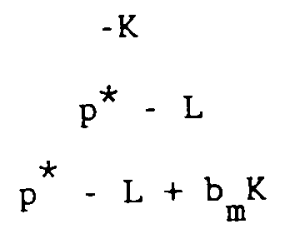

\section{Proposed System}

0

$$
\begin{aligned}
& p^{\star}-a_{t} K-L \\
& p^{\star}-a_{m} K-L
\end{aligned}
$$

Under the current system it would spend $K$ dollars in period 0 . Then in each of periods 1 through $m$ it would receive $\mathrm{p}^{\star}$ and spend $L$. Finally there would be a new auction in period $m$. If the firm loses, it receives $b_{m} k$. If it wins the auction, it must necessarily also receive a profit stream equal to $\mathrm{b}_{\mathrm{m}} \mathrm{K}$ in discounted present value, however. This is because the auction price will be bid down so that all other firms would earn zero profits if they won. This means they would earn profits of $b_{m} k$ before paying $b_{m} k$ for the asset. Therefore one can view the firm as receiving $b_{m} K$ dollars in period $m$ and nothing thereafter whether it wins or loses the next auction.

Under the proposed system the winner incurs no costs in period 0 . Then in each of periods 1 through $m i t$ zeceives its bid of $p^{*}$, pays ${ }_{t} k$ to the bond-issuing authority and $\mathrm{L}$ for labor. Its net present value of profits from future auctions should be zero because it has no advantage over other firms. Therefore one can view all subsequent cash flows as zero.

Proposition 4 presents the net present value of cash flows under each system and, in particular, shows that they are equal. 


\section{Proposition 4:}

In Case \#1, net present value of cash flows under both systems are equal and given by

(4.1) $\quad \mathrm{V}\left(\mathrm{K}, \mathrm{L}, \mathrm{a}, \mathrm{p}^{*}\right)=\frac{\phi(\mathrm{m})}{\mathrm{R}}\left(\mathrm{p}^{*}-\mathrm{L}\right)-\left\{\sum_{t=1}^{\mathrm{m}} \frac{\mathrm{a}_{t}}{(1+\mathrm{R})^{t}}\right\} \mathrm{K}$.

proof:

The proof is straightforward given the fact that

(4.2) $\frac{b_{t}}{(1+R)^{t}}=1-\sum_{i=1}^{t} \frac{a_{i}}{(1+R)^{i}}$.

QED.

A comparison of (3.21) and (4.1) shows that the objective function under regulatory $\mathrm{lag}$ is the same as under the franchise auction (when $\mathrm{P}_{t}^{*}$ is set equal to $\mathrm{p}^{*}$ ). Therefore, the same values of capital and labor are chosen as under regulatory lag. In particular the results of Corollaries 2 and 3 hold. The major result is Corollary 2. It shows that the firm makes the same capital labor choices under both systems. However the results of Corollary 3 are also interesting. They show that a franchise auction will generate firstbest incentives if and only if the constant amortization schedule is used to calculate book value (for the current system) or to calculate payments to the bond-issuing authority (for the proposed system). Accelerated (decelerated) amortization schedules will cause inefficiently low (high) capital labor ratios. 
As described above, the equilibrium bid $\mathrm{p}^{*}$ is simply the value which results in the incumbent earning zero profits. This is given by solving (4.3) $\quad V\left(K_{e}, L_{e}, a, p^{*}\right)=0$ for $\mathrm{p}^{*}$ where $\left(\mathrm{K}_{\epsilon}, \mathrm{L}_{\mathrm{e}}\right)$ denote the equilibrium choices of capital and labor.

\section{Case \#2: Unobservable Effort}

Now consider the situation where the firm can engage in unobservable effort to lower costs. As in section 3, assume that the firm winning the auction in period zero chooses two effort level- $e_{L}$ and $e_{K}$, which determine the amount of capital and labor which must be supplied to produce $x$ units of output according to $L\left(e_{L}\right)$ and $K\left(e_{K}\right)$.

In Section 3 the question of whether effort-induced cost reductions would transfer to another firm did not need to be considered, since only one firm existed. However, now this becomes an issue. It will be shown that whether transferability exists or not has an important impact on the results. The extent to which different types of cost reductions will transfer probably varies greatly. At one extreme, if effort is exerted to identify a superior type of machine, probably all of the cost-reduction could be transferred to a new franchise holder by transferring the machine. However, if effort is exerted to develop an efficient upper level management team perhaps none would be transferred.

First consider the case where effort-induced cost reductions are transferable. As in the basic model, the major task is to determine the firm's effort choices given its winning bid. The effort choices will be seen 
to be independent of the bid. Thus the equilibrium bid is simply that which results in zero profits given the predicted effort levels. Suppose that a firm has won the auction in period 0 by bidding $p^{*}$. The cash flows given it chooses effort levels $e_{K}$ and $e_{L}$ are as follows.

Table 4.2

Cash Flows for Case \#2 Under Transferability

Period

0

$1, \ldots, \mathrm{m}-1$

m
Current System

$$
-e_{L}-e_{K}-K\left(e_{K}\right)
$$$$
p^{*}-L\left(e_{L}\right)
$$$$
p^{*}-L\left(e_{L}\right)+b_{m} K\left(e_{K}\right)
$$

Proposed System

$$
\begin{aligned}
& -e_{L}-e_{K} \\
& p^{*}-a_{t} K\left(e_{K}\right)-L\left(e_{L}\right) \\
& p^{*}-a_{t} K\left(e_{K}\right)-L\left(e_{L}\right)
\end{aligned}
$$

The reasoning underlying the calculation of the values in Table 4.2 is similar to that for Table 4.1 so will not be repeated.

Proposition 5 presents the net present value of cash flows under each system and, in particular, shows they are equal.

\section{Proposition 5}

In Case \#2, given transferability, the net present values of cash flows for both system are equal and given by

(4.4) $\quad V\left(e_{K}, e_{L}, a, p^{*}\right)=-e_{K}-e_{L}+\frac{\phi(m)}{R}\left(p^{*}-L\left(e_{L}\right)\right)-\left(\sum_{t=1}^{m} \frac{a_{t}}{(1+R)^{t}}\right) K\left(e_{K}\right)$ 
proof:

The proof is straightforward given (4.2).

QED.

A comparison of (4.4) and (3.28) shows that the objective function under regulatory $\mathrm{lag}$ is the same as under the franchise auction (when $\mathrm{p}_{t}^{*}$ equals $\mathrm{p}^{*}$ ). Therefore the same values of capital and labor are chosen as under regulatory lag. In particular the results of Corollaries 4 and 5 hold. The major result is Corollary 4. It shows that the firm makes the same effort level choices under both systems. Corollary 5 shows that the firm chooses effort levels strictly less than the first-best. The intuition for this latter result is clear. The incumbent knows that the next auction will take away all benefits of cost reduction. Therefore it engages in effort only to the extent that it can be justified by $m$ periods of savings.

Now consider the case where effort-induced cost reductions are not transferable. It will be assumed that, if a new incumbent wins the franchise and the existing capital is still useful, the new incumbent must immediately incur the same effort levels as the previous incumbent in order to operate the facility. This means that bids by non-incumbents in period m will allow the incumbent to earn a profit of $e_{K}+e_{L}$ more than in the case of transferability. Therefore the cash flows in Table 4.2 are modified by adding $e_{K}+e_{L}$ to period $m$ for both systems.

Proposition 6 presents the net present value of cash flows for this case.

\section{Proposition 6}

In Case \#3 the net present value of cash flows to a period 0 incumbent under non-transferability are the same under both systems and given by 
(4.5) $V\left(e_{K}, e, a, p_{L}\right)=-\phi(m)\left\{e_{K}+e_{L}\right\}+\frac{\phi(m)}{R}\left\{p^{*}-L\left(e_{L}\right)\right\}-\left(\sum_{t=1}^{m} \frac{{ }^{a} t}{(1+R)^{t}}\right) K\left(e_{K}\right)$

proof:

Simply add

(4.6)

$$
\frac{e_{K}+e_{L}}{(1+R)^{m}}
$$

to $(4.4)$

QED.

As usual, the incentives are the same under both systems. The more surprising conclusion regards the optimality of the effort levels chosen. This result is described in Corollary 6.

\section{Corollary 6:}

Suppose cost reductions due to effort are non-transferable. Then:

(i) The equilibrium value of $\mathrm{e}_{\mathrm{L}}$ is first-best.

(ii) The equilibrium value of $e_{K}$ is equal to (greater than, less than) the first-best level for every $\mathrm{m} \in\{1, \ldots, \mathrm{n}\}$ if and only if $\mathrm{a}$ is equal to (accelerated relative to, decelerated relative to) the constant amortization schedule. 
proof:

(i) From (4.5) the equilibrium value of $e_{L}$ minimizes

(4.7) $\quad R e_{L}+L\left(e_{L}\right)$.

From (3.26) the optimal value of $e_{L}$ minimizes (4.7) as well. Therefore they are equal.

(ii) From (4.5) the equilibrium value of $e_{K}$ minimizes

$$
\phi(m) e_{k}+\sum_{i=1}^{m} \frac{{ }^{a} t}{(1+R)^{t}} k\left(e_{K}\right) .
$$

From (3.26) the optimal value minimizes

(4.9) $\quad e_{K}+\left(\frac{(1+R)^{n}}{(1+R)^{n}-1}\right) K\left(e_{K}\right)$.

Therefore since $K$ is strictly decreasing and convex, the equilibrium value is equal to the optimal value for every $m$ if and only if

$(4.10)$

$$
\frac{\sum_{t=1}^{m} \frac{a_{t}}{(1+R)^{t}}}{\phi(m)}=\frac{(1+R)^{n}}{(1+R)^{n}-1}
$$

is true for every $m \in\{1, \ldots, n\}$. This determines $n$ linear equations in the $n$ unknowns $\left(a_{1}, \ldots, a_{n}\right)$. As in the proof of Corollary 3 , the solution is the 
constant amortization schedule. The remainder of the proof is the same as for part (ii) of Corollary 3.

QED .

Therefore first-best effort levels can be achieved when effort is nontransferable. The intuitive explanation for this is that the nontransferability of the benefits of effort allows the utility to fully capture the benefits. Therefore it chooses the first-best effort level. Two remarks should be noted about this result. First, consumers are the ultimate beneficiaries of this improved efficiency. Although the initial incumbent gets to keep the benefits from effort he paid for this right with his initial bid of $\mathrm{p}^{*}$. Thus the incumbent makes zero profit overall. Second, the result suggests that institutional devices which allow a firm to be somewhat uncooperative in transferring its knowledge to a new incumbent might paradoxically be useful. Note however that this conclusion depends critically on the ability of the initial auction to extract the rents which will subsequently accrue from non-transferability.

\section{Other Issues}

\section{A. Introduction}

This section will briefly consider how the proposed system might deal with two special issues, construction work in progress and inflation.

\section{B. Construction Work in Progress}

New facilities can take a number of years to construct. Utility commissions typically do not allow utilities to enter construction costs into the rate base as they are incurred. Rather, the utility accumulates these 
costs together with interest on these costs beginning from when they are incurred. Then on the day the plant becomes operational, the entire amount is entered into the rate base.

There are two possible explanations for this practice. The first is that commissions want consumers to only pay for services they are currently using. Therefore rates should not reflect the cost of new capacity until consumers are receiving electricity produced from the new capacity. The second reason is that commissions may feel this practice increases their ability to "punish" the firm when the plant is completed and about to become operational. At this time the commission conducts a review to determine if all expenditures have been prudent and if the facility is still needed. As a theoretical matter, the commission could demand a refund of any imprudent expenditures and/or not allow an unneeded facility in the rate base regardless of whether it had allowed expenditures to enter the rate base as incurred. However, as a practical matter, it may be easier to do this if no expenditures have received the aura of approval generated by acceptance into the rate base.

Under the proposed system, construction work in progress could be treated in a similar fashion to the current system. Namely, the commission could hold a formal hearing deciding whether to enter the facility into the rate base when it was ready to become operational. To the extent that expenditures were prudent and the facility was needed, the expenditures with accumulated interest would then be entered into the rate base and immediately depreciated 100\%. At the other extreme, the commission could allow expenditures into the rate base as they were incurred and depreciate them $100 \%$ as they enter. Intermediate policies would also be possible. Namely, the commission could allow some fraction, $\alpha$, of expenditures into the rate base as they are 
incurred but leave $(1-\alpha)$ of the expenditures unreimbursed until a formal hearing prior to commencement of operation.

Note that the first reason for delaying entry into the rate base described above does not apply for the proposed system. Namely, the proposed system does not require that revenues received by the firm for capital expenditures in any given period equal consumer expenditures in the same period. Therefore one could reimburse the firm for expenses as it incurred them, but not increase rates consumers pay until the facility was producing electricity, if this was thought to be desirable.

Therefore the rationale for choosing a to be less than 1008 in the proposed system must depend on the second reason. It is unarguably the case that withholding some payment until project completion would increase the commission's ability to force the utility to absorb a loss. This is because the bond posted by the utility under the proposed system would be much smaller than the implicit bond posted under the current system. Therefore the construction cost of a new facility may dwarf the size of the posted bond under the proposed system and the commission would be unable to force the utility to absorb a loss equal to the construction cost. However, reducing the size of the bond in order to reduce hold-up costs was the explicit goal of the proposed policy. Furthermore, the time of the entry decision into the rate base is when the potential for hold-up is greatest since the amount of unreimbursed assets is greatest, and the legal restrictions on the commission are fewest. In fact, the current unwillingness of utilities to invest may be spawned precisely by fears that they will be forced to bear substantial losses when the facility is reviewed prior to becoming operational. This has been the case for nuclear plants, for example. 
Therefore, if the hold-up problem is significant enough to warrant adopting the proposed system, it is presumably also significant enough to warrant setting $\alpha$ equal to or at least close to 1008. However, it may be useful to set $\alpha$ somewhat lower than 1008 , perhaps 908 for example. The firm would then receive progress payments equal to 908 of its costs as the facility was constructed. The remaining 108 would be given to the firm upon "satisfactory" completion where "satisfactory" was determined as it now is. Thus the utility would essentially post an additional bond equal to a fraction of the cost for any major facility's construction. The reason for this is that the need to create good incentives may be especially important when a utility chooses and constructs new facilities. Thus the optimal tradeoff between incentive provision and preventing the hold-up problem may shift somewhat towards the former goal. Note, however, that leaving perhaps 108 of the payment potentially disallowable is quite different from the current situation where 1008 is potentially disallowable.

\section{Inflation}

The proposed system has been described for the case where there is no inflation. However, it can be easily adopted to the case where inflation exists and cannot be predicted. It is straightforward to show that many of the results of the previous two sections' formal models continue to hold true for the adapted model when they are interpreted as applying to real levels. For example the firm has incentives to choose the first-best input mix when real amortization payments are constant over time. This section will not perform any of this formal analysis, however. It will simply describe how the proposal would work when there is inflation. 
Suppose the utility purchases an asset in period 0 for $K$ dollars. Then let $I_{t}$ be the inflation rate which actually occurs in period $t$ as measured by some published index. ${ }^{12}$ Suppose that the asset is projected to last $n$ years. Then government would sell bonds which promise a payoff in year $t$ of

(5.1) $\sum_{i=1}^{t}\left(1+I_{i}\right)$

dollars for years 1 through $n .13$ It would sell sufficient bonds to raise $K$ dollars. Suppose that $B$ bonds are required - - i.e. - each bond sold for a price of $\mathrm{K} / \mathrm{B}$ dollars. Then the utility would be required to pay the bondissuing authority

$$
B\left[\sum_{i=1}^{t}\left(1+I_{i}\right)\right]
$$

at the end of period $t$. Suppose that $p_{0}$ was the price of electricity established in period 0 through a rate hearing. Then the price in subsequent periods would be adjusted upwards automatically to reflect inflation even if the no rate hearing occurred. That is the price in period $t$ would automatically be

$$
p_{t}=p_{0}^{t}{ }_{i=1}^{\pi}\left(1+I_{i}\right) .
$$


A number of remarks should be noted about this system. First, it will result in a constant real price for electricity. This presumably is desirable from the standpoint of smoothing consumer expenditures ${ }^{14}$ and it can also be shown to create incentives for the firm to choose the first-best capital labor ratio under regulatory lag or franchise auctions. However one could obviously choose a different real amortization schedule if desired. Second, bondholders will not receive a fixed nominal payment as is typically the case. Rather they will receive a fixed real payment (at least as measured by the given index.) It may well be that prospective bondholders would actually view such a bond as less risky than one which yielded a fixed nominal return. Third, since both prices and rental payments on capital will rise automatically with inflation, there should be no need for more frequent rate hearings during periods of rapid inflation. 


\section{References}

Bailey, E. and R. Coleman [1971], "The Effect of Lagged Pegulation in the Averch-Johnson Model, " Bell Journal of Economics, 2, 278-272.

Baumol, W.J., [1971], "Optimal Depreciation Policy: Pricing the Products of Durable Assets, " Be11 Journal of Economics, 2, 638-656.

BaumoI, W.J. and A.K. Klevorick [1970], "Input Choices and Rate-of-Return Regulation: An Overview of the Discussion," Bell Journal of Economics, 1 , $162-190$.

Bawa, V. and D. Sibley [1980], "Dynamic Behavior of a Firm Subject to Stochastic Regulatory Review," International Economic Review, 21, 627642.

Demsetz, Harold [1968]. "Why Regulate Utilities?", Journal of Law and Economics, $11,55-68$.

Gilbert, Richard [1982], "The Regulation Trap," mimeo.

Gilbert, Richard and David Newberry [1988], "Regulation Games, "U.C. Berkeley Economics Department Working Paper 8879.

Greenwald, Bruce [1980], "Admissible Rate Bases, Fair Rates of Return and the Structure of Regulation," The Journal of Finance, 35, 359-368.

Greenwald, Bruce [1984], "Rate Base Selection and the Structure of Regulation," Rand Journal of Economics, 15, 85-95.

Joskow, Paul and Richard Schmalensee, [1983]. Markets For Power, MIT Press, Cambridge .

Klein, Benjamin, Robert Crawford and Armen Alchian, [1978], "Vertical Integration, Appropriable Rents, and the Competitive Contracting Process," Journal of Law and Economics, 21, 297-326. 
Klevorick, A. [1973], "The Behavior of a Firm Subject to Stochastic Regulatory Review," Bell Journal of Economics, 4, 57-88.

Kolbe, A.L., [1983], "Inflation-driven Rate Shocks: The Problem and Possible Solutions", Public Utilities Fortnightly, February 17, 26-34.

Kolbe, Lawrence, James Reed, Jr., and George Hall [1984], The Cost of Capital, MIT Press, Cambridge, Massachusetts.

Meyers, Stewart, Lawrence Kolbe, and William Tye [1985], "Inflation and Rate of Return Regulation," in Transportation Economics. Volume 2, edited by Theodore Keeler, JAI Press, Inc., Greenwich, Connecticut.

Navarro, Peter, Bruce Petersen, and Thomas Stauffer [1981], "A Critical Comparison of Utility-Type Ratemaking Methodologies in Oil Pipeline Regulation," Bel1 Journal of Economics, 12, 392-412.

Panzar, John [1988], "Economic Depreciation Principles," mimeo.

Williamson, Oliver [1975], Markets and Hierarchies: Analysis and Antitrust Implications, The Free Press, New York, N.Y.

Williamson, 0liver [1976], "Franchise Bidding for Natural Monopolies - In General and With Respect to CATV, "Bell Journal of Economics, 7, 73-104. Williamson, Oliver [1983], "Credible Commitments: Using Hostages to Support Exchange", American Economic Review, 73, 519-540.

Williamson, Oliver [1985], The Economic Institutions of Capitalism, The Free Press, New York, N.Y.

Zimmerman, Martin [1988], "Regulatory Treatment of Abandoned Property: Incentive Effects and Policy Issues, "Journal of Law and Economics, 31, $127-144$ 


\section{Notes}

1. See for example, Baumol [1971], Greenwald [1980,1984], Kolbe [1983], Meyers, Kolbe, and Tye [1985], and Panzar [1988].

2. Both of these theories will be explained in more detail in Section 2 .

3. See the references in footnote 1 above.

4. See Joskow and Schmalensee [1983] pages 85-86 and Kolbe, Reed and Hall [1986], pages 31-33.

5. Whether such an intermingling would in fact be a good idea will not be considered by this paper. Presumably the advantages of prohibiting this intermingling include the following. First it guarantees that total consumer surplus exceeds total cost. Second, it guarantees that government will not use the utility as a tax-raising device.

6. Note that this subject to the proviso that penalties larger than the bond cannot be levied.

7. See Bailey and Coleman [1971], Baumol and Klevorick [1970], Bawa and Sibley [1980] and Klevorick [1973].

8. Once again this is subject to the proviso that penalties larger than the bond cannot be levied.

9. See Williamson $[1976,1985]$ and Goldberg [1976].

10. The major results of this section are that (i) both systems cause firstbest choices to be made when the constant amortization schedule is used, and (ii) both systems cause more than (less than) the first best level of capital to be used if the amortization schedule is decelerated (accelerated) relative to the constant amortization schedule. These results continue to hold even if the firm and bond-issuing authority are allowed to have different costs of capital.

11. The fact that a large number of firms compete for the franchise is taken to imply that potential entrants will always bid the price down to the level where they earn zero profits.

12. For example an inflation rate of $10 \%$ in period $t$ means that $I_{\text {f }}$ equals .10. Since inflation will not affect all input costs similarly, this method will of course only be approximately correct.

13. For expositional simplicity, the proposal is being described for the case where the bonds are amortized through a series of constant real payments. It would obviously also be possible to choose amortization schedules such that the real level of payments increased or decreased over time if this was desired.

14. See Kolbe [1983] and Meyers, Kolbe, and Tye [1985]. 